\title{
HEALTH STATUS AND LIFESTYLE HABITS OF VULNERABLE, COMMUNITY-DWELLING OLDER PEOPLE DURING THE COVID-19 LOCKDOWN
}

\author{
M. MACHÓN ${ }^{1,2,3}$, M. MATEO-ABAD ${ }^{2,3}$, K. VROTSOU ${ }^{1,2,3}$, I. VERGARA $^{1,2,3}$ \\ 1. Instituto de Investigación Sanitaria Biodonostia, Grupo de Atención Primaria, San Sebastián, Spain; 2. Red de Investigación en Servicios de Salud en Enfermedades Crónicas \\ (REDISSEC), Baracaldo, Spain; 3. Instituto de Investigación en Servicios de Salud Kronikgune, Baracaldo, Spain. \\ Corresponding author: Mónica Machón Sobrado, Instituto de Investigación Sanitaria Biodonostia, Paseo Doctor Beguiristian s/n, 20014 San Sebastián (Gipuzkoa), Spain, \\ Tel. +34943006086; Fax: +34943006250; e-mail: monica.machonsobrado@osakidetza.eus
}

\begin{abstract}
This study evaluated the health status and lifestyle habits of vulnerable, community-dwelling older adults during the first COVID-19 lockdown in Spain. A telephone assessment was carried out in 38 individuals ( $71 \%$ women), with a Barthel index $\geq 85$ who were frail or had a high risk of falls. Data were compared with those from an assessment performed 9 months earlier. In the latter part of the lockdown, a high percentage of the studied individuals showed difficulties in walking up 10 steps and reported sleep problems $(66 \%)$ and pain $(74 \%)$. On the other hand, participants were not anxious/depressed (71\%) and the majority did not report loneliness $(60 \%)$. Compared to the earlier assessment, we identified a decline in functional capacity and worsening of nutritional status, but an increase in family support. Efforts should be made to implement intervention programs seeking to avoid accelerated decline under the current pandemic situation, and especially during possible new lockdowns.
\end{abstract}

Key word: COVID-19, older people, lockdown, health, lifestyle habits.

Published online April 5, 2021, http:/ / dx.doi.org/10.14283/jfa.2021.12

\section{Introduction}

The SARS-Cov-2 virus has caused a worldwide pandemic. By September 7th 2020, the total number of confirmed cases in Spain were 525,549 (1). The highest severity and mortality rates of the coronavirus disease 2019 (COVID-19) are seen in older people (2). To deal with this health crisis, the Spanish Government declared the state of alarm from March 14th 2020 to June 21st 2020 (3). During the first part of this lockdown, until May 2nd 2020, people were only allowed to leave their homes to buy food or medicines, attend to a medical center, go to a bank or insurance company, go to work, care for vulnerable individuals or complete other activities considered essential (3). After that, a four-phase plan for easing restrictions towards the so-called "new normality" was asymmetrically applied across Spain.

A prolonged stay indoors alters lifestyle habits, with individuals potentially reducing their physical activity, eating a less healthy diet and/or experiencing a lack of social contact (4). Consequently, the health of the population may be affected. Relatively few studies so far have explored the changes in health status and lifestyle habits during a period of confinement in different age groups (5-7).

The objective of this study was to assess the health status and lifestyle habits of vulnerable, community-dwelling older adults during the first COVID-19 lockdown in Spain, comparing results with data collected at a previous time point.

\section{Methods}

\section{Design and study population}

This study was carried out on a sample of individuals who participated in a previous study (8). The initial sample included community-dwelling people aged $\geq 70$ years, living in Guipúzcoa (Basque Country, Spain), with a Barthel index $\geq 85$ $(9,10)$ who met one of the following criteria: frailty, based on the Timed up and go test $\geq 20$ seconds $(11,12)$ or a high risk of falls (12).

\section{Data collection}

For this study, a telephone assessment was performed by a nurse and a social worker between April 27th and May 14th 2020. In addition, we used data that had been collected 9 months earlier through face-to-face interviews, conducted by another nurse and social worker in a primary care center and at the participants' home. During the interviews, information was collected on individuals' health status, lifestyle habits, social life, and home and environment conditions.

\section{Variables}

The variables assessed during the telephone interviews were the following: age, sex, ability to perform basic (Barthel index $(9,10)$ ), and instrumental (Lawton test (13)) activities of daily living, body mass index, frequency of consumption of white meat, fish and eggs (adequate: daily and $\geq 3$ times/week; inadequate: 1-2 times/week, $<1$ time/week and never or almost never), Mini Nutritional Assessment-Short Form (MNA, score 


\section{THE JOURNAL OF FRAILTY \& AGING}

0-14 points) (14), physical activity (based on the question, "Do you regularly do at least 30 minutes of physical activity each day or 4 hours a week?"), hours of sleep per day, living arrangements and family support (based on the question, "Do you have enough family support?"). The previous assessment collected information on the aforementioned variables, and also level of education and cognitive status (Memory Alteration Test, score 0-50 points (15)).

Furthermore, the telephone interview included two questions from the FRAIL scale (16): "How much of the time during the past 4 weeks have you felt tired?" and "By yourself and without using aids, do you have any difficulty walking up 10 steps without resting?". Participants were also asked to report any falls experienced in the previous 4 weeks; self-perceived health (assessed with one item, grouping response options as, poor [fair, poor and very poor] and good [very good and good]; diet in relation to frequency of fruit, vegetable and legumes intake; and sleep habits, with two questions: "Do you take pills for sleep?" and "How many times in the last 4 weeks have you had difficulties falling asleep?". Lastly, health related quality of life was explored with the EuroQol EQ-5D-5L scale (17) and overall loneliness with the six-item De Jong Gierveld Loneliness scale (not lonely: 0-1; lonely: 2-6) $(18,19)$.

\section{Statistical analysis}

Categorical variables were described as frequencies with percentages and continuous variables as means with standard deviations (SD). Paired comparisons were carried out using McNemar's test for categorical variables and Student's paired t-test for continuous variables. Statistical analyses were performed with the free statistical software $\mathrm{R}$, version 3.4.0.

\section{Ethical aspects}

The study was approved by the Comité de Ética de la Investigación con medicamentos de Euskadi (CEIm-E, $12 / 2020)$. Verbal consent was requested for participation in this research.

\section{Results}

Of the 48 individuals (69\% women, mean age: 82.0 years, $\mathrm{SD}=5.8)$ previously assessed, 10 were excluded from this study due to: death $(n=1)$, hospitalization $(n=1)$, refusal to participate $(n=8)$. The final sample consisted of 38 individuals (71\% women).

During the latter part of the lockdown, a $35 \%$ of the individuals reported having felt often tired in the previous 4 weeks, and most had difficulties in walking up 10 steps without resting (Table 1). Although a high percentage woke up rested in the morning, $46 \%$ took sleeping pills and $66 \%$ had had difficulties sleeping in the previous 4 weeks. Forty-two percent of participants reported poor self-perceived health. The majority reported slight or moderate pain or discomfort but they were not anxious or depressed $(71 \%)$ and did not experience loneliness $(60 \%)$
Table 1

Characteristics of the sample during the latter part of the lockdown

\begin{tabular}{|c|c|c|}
\hline Variables & Total $(n=38)$ & Missing \\
\hline Age, years, mean (SD) & $83.0(6.3)$ & 0 \\
\hline Women & $27(71)$ & 0 \\
\hline Level of education* & & 0 \\
\hline Primary or lower & $37(97)$ & \\
\hline Secondary or higher & $1(3)$ & \\
\hline Memory Alteration Test* & & 0 \\
\hline No cognitive impairment ( $\geq 38$ points) & $28(74)$ & \\
\hline Mild cognitive impairment (29-37) points) & $9(24)$ & \\
\hline Early stage Alzheimer's disease ( $\leq 28$ points) & $1(2)$ & \\
\hline Fatigue during the last 4 weeks & & 1 \\
\hline Occasionally or never & $24(65)$ & \\
\hline All of the time or most of the time & $13(35)$ & \\
\hline Having difficulties in walking up 10 steps without resting & $24(63)$ & 0 \\
\hline Falls in the last 4 weeks & $1(3)$ & 0 \\
\hline Inadequate fruit intake & $2(5)$ & 1 \\
\hline Inadequate vegetable intake & $3(8)$ & 0 \\
\hline Inadequate legume intake & $25(66)$ & 0 \\
\hline Taking sleeping pills & $17(46)$ & \\
\hline Difficulties sleeping in the last 4 weeks & & 0 \\
\hline Never & $13(34)$ & \\
\hline Some days & $17(45)$ & \\
\hline Several days & $5(13)$ & \\
\hline Everyday & $3(8)$ & \\
\hline Get up rested in the morning & & 0 \\
\hline Most of the time & $26(68)$ & \\
\hline Sometimes & $5(13)$ & \\
\hline Rarely or never & $6(16)$ & \\
\hline Don't know & $1(3)$ & \\
\hline Poor self-perceived health & $16(42)$ & 0 \\
\hline Mobility, EQ-5D-5L & & 0 \\
\hline I have no problems in walking about & $10(26)$ & \\
\hline I have slight problems in walking about & $15(39)$ & \\
\hline I have moderate problems in walking about & $12(32)$ & \\
\hline I have severe problems in walking about & $1(3)$ & \\
\hline I am unable to walk about & $0(0)$ & \\
\hline Self-care, EQ-5D-5L & & 0 \\
\hline I have no problems washing or dressing myself & $27(71)$ & \\
\hline I have slight problems washing or dressing myself & $8(21)$ & \\
\hline I have moderate problems washing or dressing myself & $1(3)$ & \\
\hline I have severe problems washing or dressing myself & $0(0)$ & \\
\hline I am unable to wash or dress myself & $2(5)$ & \\
\hline \multicolumn{3}{|l|}{ Usual activities, EQ-5D-5L } \\
\hline I have no problems doing my usual activities & $15(39)$ & 0 \\
\hline I have slight problems doing my usual activities & $18(47)$ & \\
\hline I have moderate problems doing my usual activities & $4(11)$ & \\
\hline I have severe problems doing my usual activities & $1(3)$ & \\
\hline I am unable to do my usual activities & $0(0)$ & \\
\hline
\end{tabular}




\section{HEALTH OF OLDER PEOPLE DURING THE COVID-19 LOCKDOWN}

Table 1 (continued)

Characteristics of the sample during the latter part of the lockdown

\begin{tabular}{lcc}
\hline Variables & Total $(\mathbf{n = 3 8})$ & Missing \\
\hline Pain/Discomfort, EQ-5D-5L & 0 \\
I have no pain or discomfort & $10(26)$ & \\
I have slight pain or discomfort & $16(42)$ & \\
I have moderate pain or discomfort & $12(32)$ & 0 \\
I have severe pain or discomfort & $0(0)$ \\
I have extreme pain or discomfort & $0(0)$ \\
Anxiety/Depression, EQ-5D-5L & $27(71)$ \\
I am not anxious or depressed & $9(24)$ \\
I am slightly anxious or depressed & $1(3)$ \\
I am moderately anxious or depressed & $1(3)$ \\
I am severely anxious or depressed & $0(0)$ \\
I am extremely anxious or depressed & \\
De Jong Gierveld Loneliness -Scale & $14(40)$ \\
Lonely & $21(60)$ \\
Not lonely & 3 \\
\hline Numbers are n (\%) unless otherwise stated; *These variables were collected only during \\
the initial assessment.
\end{tabular}

Functional capacity declined over time, for both basic and instrumental activities of daily living. Based on the Barthel index, fewer were able to walk independently without assistance $(92 \%$ vs. $74 \%, \mathrm{p}=0.008)$ or climb stairs $(92 \%$ vs. $71 \%, \mathrm{p}<0.001)$ after the confinement. Regarding nutritional status, the participants' BMI decreased $(\mathrm{p}<0.001)$. At the same time, the normal MNA seen in all cases (100\%) during the first assessment worsened to a risk of malnutrition and malnourishment in $32 \%$ and $3 \%$ of the sample, respectively. Participants also reported having fewer hours of sleep $(\mathrm{p}=0.001)$. At the same time, family support was higher than in the pre-lockdown period $(\mathrm{p}=0.005)$.

\section{Discussion}

The assessment of a group of vulnerable, communitydwelling older individuals in the latter part of the first COVID-19 lockdown period revealed several issues that merit discussion. Our data show more sleep and mobility problems than in a recent previous assessment. Most of the individuals also experienced a certain level of pain, but they were neither anxious/depressed nor lonely. Similarly, in Losada-Baltar et al. (5), older people reported lower levels of anxiety than middle aged adults and younger group. The lowest loneliness levels were reported by middle aged adults, followed by older adults and younger participants. The older population seems to have greater resilience and capacity to adapt to this kind of situation (5). Nonetheless, overall, the health status of the participants had worsened, compared to the first assessment. The decline in functional capacity, both for basic and instrumental activities of daily living was particularly striking. This deterioration may be associated with a higher risk of adverse events, such as hospitalization or death. Furthermore, we observed changes in dietary patterns, with a lower consumption of protein. As a result, nutritional status worsened from normal to at risk

Table 2

Comparison between the initial assessment and the latter part of the lockdown

\begin{tabular}{|c|c|c|c|c|c|}
\hline Variables & Initial assessment $(n=38)$ & Missing & Latter part of the lockdown $(n=38)$ & Missing & p-value \\
\hline \multicolumn{6}{|l|}{ Barthel index score } \\
\hline Mean (SD) & $96.6(4.7)$ & 0 & $91.8(11.1)$ & 0 & 0.003 \\
\hline Categories & & 0 & & 0 & 0.023 \\
\hline$<95$ & $8(21)$ & & $15(39)$ & & \\
\hline $95-100$ & $30(79)$ & & $23(61)$ & & \\
\hline Lawton score, mean (SD) & $6.7(1.5)$ & 0 & $5.4(1.6)$ & 0 & $<0.001$ \\
\hline Body mass index, mean (SD) & $29.7(4.1)$ & 0 & $27.8(3.5)$ & 8 & $<0.001$ \\
\hline Inadequate white meat intake & $19(50)$ & 0 & $20(53)$ & 0 & 1.000 \\
\hline Inadequate fish intake & $16(42)$ & 0 & $19(53)$ & 2 & 0.343 \\
\hline Inadequate eggs intake & $15(39)$ & 0 & $27(71)$ & 0 & 0.006 \\
\hline Mini Nutritional Assessment-Short Form & & 4 & & 1 & $<0.001$ \\
\hline Normal (12-14) & $34(100)$ & & $24(65)$ & & \\
\hline At risk of malnutrition (8-11) & $0(0)$ & & $12(32)$ & & \\
\hline Malnourished (0-7) & $0(0)$ & & $1(3)$ & & \\
\hline Physical activity (30 min/day or 4h/week) & $26(68)$ & 0 & $29(76)$ & 0 & 0.366 \\
\hline Hours of sleep, mean (SD) & $8.2(2.0)$ & 0 & $7.0(1.8)$ & 0 & 0.001 \\
\hline Living alone & $20(53)$ & 0 & $21(55)$ & 0 & 0.728 \\
\hline Having enough family support & $29(76)$ & 0 & $37(97)$ & 0 & 0.005 \\
\hline
\end{tabular}

\footnotetext{
Numbers are $\mathrm{n}(\%)$ unless otherwise stated.
} 


\section{THE JOURNAL OF FRAILTY \& AGING}

of malnutrition or malnourished in some cases. Regarding the Mediterranean diet, Rodriguez-Perez et al. (7) found that adherence in people $>51$ years, slightly increased during the confinement in Spain, while in Di Renzo et al., detected a higher adherence in 18-to 30-year-olds than in younger and older populations during the first COVID-19 lock-down in Italy (6).

This study highlights the risk that a long period at home may pose for vulnerable populations. Maintaining the health status of such individuals and helping them to avoid rapid deterioration under the current pandemic situation is a challenging task. There is a clear necessity for programs specifically designed to meet their needs. Promoting physical activity and helping individuals maintain healthy dietary and sleep patterns should be the focus of such programs. In particular, a multicomponent exercise routine, with aerobic, resistance, balance, coordination and mobility training exercises, easily performed at home, would be recommended for older people $(11,20)$. Regarding diet, efforts should be made to ensure an adequate protein intake (21). Sleep problems could be addressed by a combination of non-pharmacological treatments, such as sleep hygiene education and relaxation techniques (22). These and similar interventions would be useful in the current context, as well as in case of new lockdowns

The main limitation of this study is that it is not possible to know whether the changes observed were due to the impact of the confinement or the time elapsed between the assessments. Frailty is a dynamic process, with functional status commonly worsening $(23,24)$. The sample studied was composed of initially independent but vulnerable individuals, with frailty or a high risk of falls. Therefore, the decline observed could have been spontaneous. Nonetheless, the lockdown situation is unlikely to have a positive impact on the condition of the participants. Another limitation is that the sample size is very small. Moreover, weight at the time of the telephone assessment was self-reported. This may have introduced some bias. On the other hand, during the telephone interview participants were also asked about their weight in the previous year, and values reported were similar to those measured at the initial assessment. Self-reported weight has been used in other studies $(6,7)$.

\section{Conclusions}

Functional and nutritional status and sleep patterns worsened during a COVID-19 lockdown in a group of vulnerable older individuals. The needs of this population should be considered and incorporated into interventions designed to avoid rapid decline under the current pandemic situation, and especially during any future period of confinement.

Funding: This study was supported by the Gipuzkoa Provincial Council, though the 2018 and 2019 Adinberri program (Grants number: DFG18/201 and FADIN19/002, respectively).
Conflict of interest: The authors have no conflicts of interest to declare.

\section{References}

1. Ministerio de Sanidad. Actualización $n^{\circ}$ 201. Enfermedad por el coronavirus (COVID19). 07.09.2020 (datos consolidados a las 14:00 horas del 07.09.2020). Situación en España https://www.mscbs.gob.es/profesionales/saludPublica/ccayes/alertasActual/ nCov-China/situacionActual.htm[8 September 2020, date last accessed].

2. Promislow DEL. A geroscience perspective on COVID-19 mortality [published online ahead of print, 2020 Apr 17]. J Gerontol A Biol Sci Med Sci 2020;glaa094.

3. Boletín Oficial del Estado. Real Decreto 463/2020, de 14 de marzo, por el que se declara el estado de alarma para la gestión de la situación de crisis sanitaria ocasionada por el COVID-19. https://www.boe.es/diario_boe/txt.php?id=BOE-A-2020-3692 [14 August 2020, date last accessed].

4. Lippi G, Henry BM, Bovo C, Sanchis-Gomar F. Health risks and potential remedies during prolonged lockdowns for coronavirus disease 2019 (COVID-19). Diagnosis (Berl) 2020;7:85-90

5. Losada-Baltar A, Márquez-González M, Jiménez-Gonzalo L, Pedroso-Chaparro MDS, Gallego-Alberto L, Fernandes-Pires J. Diferencias en función de la edad y la autopercepción del envejecimiento en ansiedad, tristeza, soledad y sintomatología comórbida ansioso-depresiva durante el confinamiento por la COVID-19. Rev Esp Geriatr Gerontol 2020 Jun 4:S0211-139X(20)30064-0.

6. Di Renzo L, Gualtieri P, Pivari $\mathrm{F}$ et al. Eating habits and lifestyle changes during COVID-19 lockdown: an Italian survey. J Transl Med 2020;18:229.

7. Rodríguez-Pérez C, Molina-Montes E, Verardo V et al. Changes in Dietary Behaviours during the COVID-19 Outbreak Confinement in the Spanish COVIDiet Study. Nutrients 2020;12:1730.

8. Machón M, Güell C, Vrotsou K, Vergara I. Diseño y pilotaje de un modelo para la valoración de la capacidad funcional en personas mayores residentes en la comunidad. Aten Primaria. 2021 Feb 19;53(4):101981.

9. Mahoney FI, Barthel DW. Functional evaluation: the Barthel index. Md State Med J 1965;14:61-5.

10. González N, Bilbao A, Forjaz MJ et al.Psychometric characteristics of the Spanish version of the Barthel Index. Aging Clin Exp Res 2018;30:489-97.

11. Ministerio de Sanidad, Servicios Sociales e Igualdad. Consensus Document on Frailty and Falls Prevention among the Elderly. The prevention and health promotion strategy of the Spanish NHS. Document approved by the Inter-territorial Council fo the National Health System on 11 June 2014.https://www.mscbs.gob.es/profesionales saludPublica/prevPromocion/Estrategia/Fragilidadycaidas.htm[14 August 2020, date last accessed].

12. Osakidetza. Plan de atención a las personas mayores (PAM). https://www.osakidetza euskadi.eus/contenidos/informacion/osk_trbg_planes_programas/es_def/adjuntos/plande-atencion-a-personas-mayores_PAM.pdf [14August 2020, date last accessed].

13. Vergara I, Bilbao A, Orive $\mathrm{M}$ et al. Validation of the Spanish version of the Lawton IADL Scale for its application in elderly people. Health Qual Life Outcomes 2012:10:130.

14. Mini Nutritional Assessment. Nestle Nutrition Institute 2014.http://www.mna-elderly com/mna_forms.html [14 August 2020, date last accessed].

15. Rami L, Molinuevo JL, Sanchez-Valle R, et al. Screening for amnestic mild cognitive impairment and early Alzheimer's disease with M@T (Memory Alteration Test) in the primary care population. Int J Geriatr Psychiatry. 2007;22:294-304.

16. Morley JE, Malmstrom TK, Miller DK. A simple frailty questionnaire (FRAIL) predicts outcomes in middle aged African Americans. J Nutr Health Aging 2012;16:601-08.

17. Herdman M, Gudex C, Lloyd A et al. Development and preliminary testing of the new five-level version of EQ-5D (EQ-5D-5L). Qual Life Res 2011;20:1727-36.

18. Gierveld JDJ, Tilburg TV A 6-Item Scale for Overall, Emotional, and Socia Loneliness: Confirmatory Tests on Survey Data. Research on Aging 2006; 28: 582-98.

19. Prieto-Flores ME, Forjaz MJ, Fernandez-Mayoralas G, Rojo-Perez F, Martinez-Martin P. Factors Associated With Loneliness of Noninstitutionalized and Institutionalized Older Adults. J Aging Health 2011; 23: 177-94.

20. Jiménez-Pavón D, Carbonell-Baeza A, Lavie CJ. Physical exercise as therapy to fight against the mental and physical consequences of COVID-19 quarantine: Special focus in older people. Prog Cardiovasc Dis 2020;63:386-88.

21. Bauer J, Biolo G, Cederholm T et al. Evidence-based recommendations for optima dietary protein intake in older people: a position paper from the PROT-AGE Study Group. J Am Med Dir Assoc. 2013 Aug;14:542-59.

22. Patel D, Steinberg J, Patel P. Insomnia in the Elderly: A Review. J Clin Sleep Med. 2018 Jun $15 ; 14: 1017-24$.

23. Espinoza SE, Jung I, Hazuda H. Frailty transitions in the San Antonio Longitudinal Study of Aging. J Am Geriatr Soc2012;60:652-60.

24. Bentur N, Sternberg SA, Shuldiner J. Frailty Transitions in Community Dwelling Older People. Isr Med Assoc J 2016;18:449-53. 